\title{
Clinical presentation of acute appendicitis in adults at the Chris Hani Baragwanath academic hospital
}

\author{
Richard Nshuti*, Deirdré Kruger and Thifheli E Luvhengo
}

\begin{abstract}
Background: Acute appendicitis is the most common surgical abdominal emergency. Delayed treatment increases the incidence of complications. The aim of this study was to investigate the presentation, incidence, and predictors of complications, and histological findings in adult patients with clinical diagnosis of acute appendicitis.

Methods: The study was a prospective observational study and included patients aged 12 years and older diagnosed with acute appendicitis. Data collected included demographic data, clinical presentation, duration of symptoms and reasons for presentation delay, diagnostic investigations, operative and histology findings, length of hospital stay, and mortality.

Results: A total of 146 patients were admitted with a mean age of 26 years ( $S D=12$ years). The male to female ratio was 1.6:1. Predominant presenting symptoms were right iliac fossa pain (95\%), nausea (80\%), and vomiting (73\%), with $63 \%$ of patients presenting 2 days after onset of symptoms. Fever was present in 15\% and only $31 \%$ of patients gave a typical history of acute appendicitis of vague peri-umbilical pain. The negative predictive values of white cell count and C-reactive protein for acute appendicitis were $28 \%$ and $50 \%$, respectively. Sensitivity of the ultrasound to detect acute appendicitis was $60 \%$ with a negative predictive value of 31\%; $30 \%$ of patients had complicated appendicitis. Histology results showed a normal appendix in $11 \%$ of patients. The 30 -day mortality rate was $1.4 \%$.

Conclusions: Patients with acute appendicitis rarely present with a typical history of vague peri-umbilical pain. The negative predictive values of both white cell count and ultrasound proved that neither of these measurements was accurate in the diagnosis of acute appendicitis. Most of our patients with complicated disease present late, with the most common reasons for this delay being lack of access to a medical clinics and prior treatment by general practitioners. Complications were higher in males and in those aged 45 years and above.
\end{abstract}

Keywords: Acute appendicitis; Complications; Delayed presentation; Negative appendicectomy

\section{Background}

Appendicectomy is the most common emergency surgical procedure worldwide. About $8 \%$ of people in Western countries will have appendicitis during their lifetime, and the incidence in the UK is about 52 per 100,000 population. However, in South Africa, the incidence is estimated to be less than 9 per 100,000. The peak incidence of acute appendicitis is between 10 and 30 years of age $[1,2]$.

\footnotetext{
* Correspondence: riminshu@yahoo.co.uk

Department of Surgery, Chris Hani Baragwanath Academic Hospital and University of Witwatersrand, Witwatersrand, South Africa
}

The diagnosis of acute appendicitis is mainly clinical and presentation of acute appendicitis may be typical or atypical. Typical presentation starts with vague periumbilical pain for several hours, which later migrates to the right iliac fossa (RIF), associated with lack of appetite, nausea, or vomiting. Atypical histories lack this typical progression and may include pain in the right lower quadrant as an initial symptom [3].

If left untreated, acute appendicitis may lead to complications, leading to inflammatory mass, appendix abscess, or rupture, with generalized peritonitis. Diagnosis of complicated acute appendicitis is clinically supplemented 
by ultrasound or CT scan $[4,5]$. However, it is common in practice to admit and observe patients with an uncertain diagnosis and to delay their surgery until the diagnosis is more definite in order to reduce the negative appendicectomy rate. Pre-admission delay on the part of the patient and post-admission delay by the surgeon are responsible for combined delay in diagnosis and definitive management [6-8].

\section{Methods}

This was a prospective observational study of patients 12 years and older (as 12 years is a lower age cut-off for admission), diagnosed and treated for acute appendicitis at the Chris Hani Baragwanath Academic Hospital (CHBAH) from May $1^{\text {st }} 2011$ to October $31^{\text {st }} 2011$.

Patients' files were reviewed on admission and after discharge. Data retrieved included patients' demographics, clinical presentation, and duration of symptoms before presentation to the hospital, results of diagnostic investigations and evidence of complicated disease at presentation, length of hospital stay, intensive care unit (ICU) admission, negative appendicectomy, and mortality rate.

Sensitivity, specificity, positive predictive value (PPV) and negative predictive value (NPV) of diagnostic investigations were calculated. An Excel sheet was used for data collection and Statistica was used for statistical analysis.

Permission to conduct the study was received from the Human Ethics Committee of the University of Witwatersrand and Research Review Board of the CHBAH.

\section{Results}

A total of 146 patients were diagnosed with acute appendicitis. The male to female ratio was 1.6:1 and their mean age was 26 years ( $\mathrm{SD}=12$ years). The duration of symptoms was 4.5 days ( $\mathrm{SD}=4$ days) and $63 \%$ of the patients presented more than two days after the onset of symptoms. Overall, the complicated appendicitis rate was $30 \%$, with the most common reason for delay in presentation being a lack of access to hospitals or clinics and to information (29\%), and prior treatment by general practitioners (19\%) (Figure 1).

Common presenting symptoms were RIF pain (95\%), vomiting (73\%), and 31\% had a typical acute appendicitis presentation and $80 \%$ had nausea (Figure 2).

The following investigations were undertaken: white cell count (WCC) in 95\%, C-reactive protein (CRP) in $89 \%$, abdominal ultrasound in $40 \%$, CT scan in $6 \%$, and diagnostic laparoscopy in $7 \%$ of the 146 patients included in this study. The median WCC and CRP were 11.5 (8.7-15.4) and 80.5 (30.3-171.3), respectively. The sensitivity, specificity, PPV, and NPV percentages of all investigations were as illustrated in Table 1.

The majority of our patients $(89 \%, 131 / 146)$ were operated on soon after admission (Figure 3). Histology results showed perforated appendix with or without generalized peritonitis in 41 patients (29\%) and normal appendix in $11 \%$ of cases (Table 2 ).

The mortality rate was $1.37 \%$ (2/146); patients who died were above 45 years of age, with comorbidities and having had more than two re-operations. There was a statistically significant difference in duration of symptoms, length of ICU and hospital stay, re-operation, and mortality in patients with complicated appendicitis when compared to uncomplicated appendicitis (Tables 3 and 4).

\section{Discussion}

Our study involved 146 patients out of a total of 3,994 patients admitted during a six-month period to the Department of Surgery at CHBAH. Signs and symptoms of acute appendicitis were dominated by abdominal pain

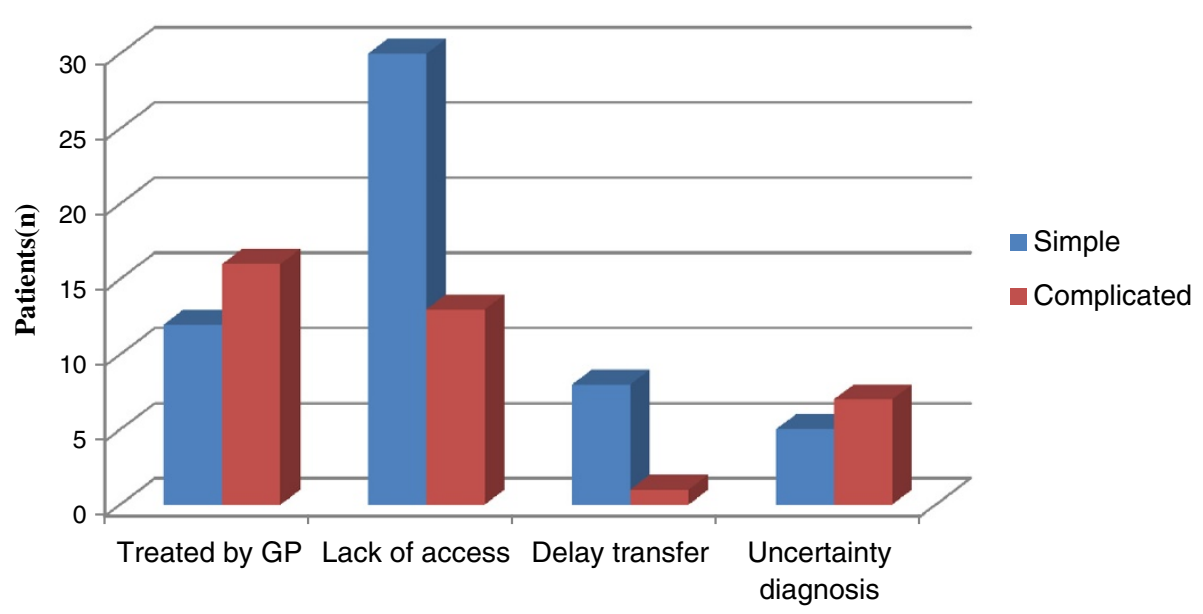

Figure 1 Reasons for delays compared to the occurrence of complicated appendicitis. 


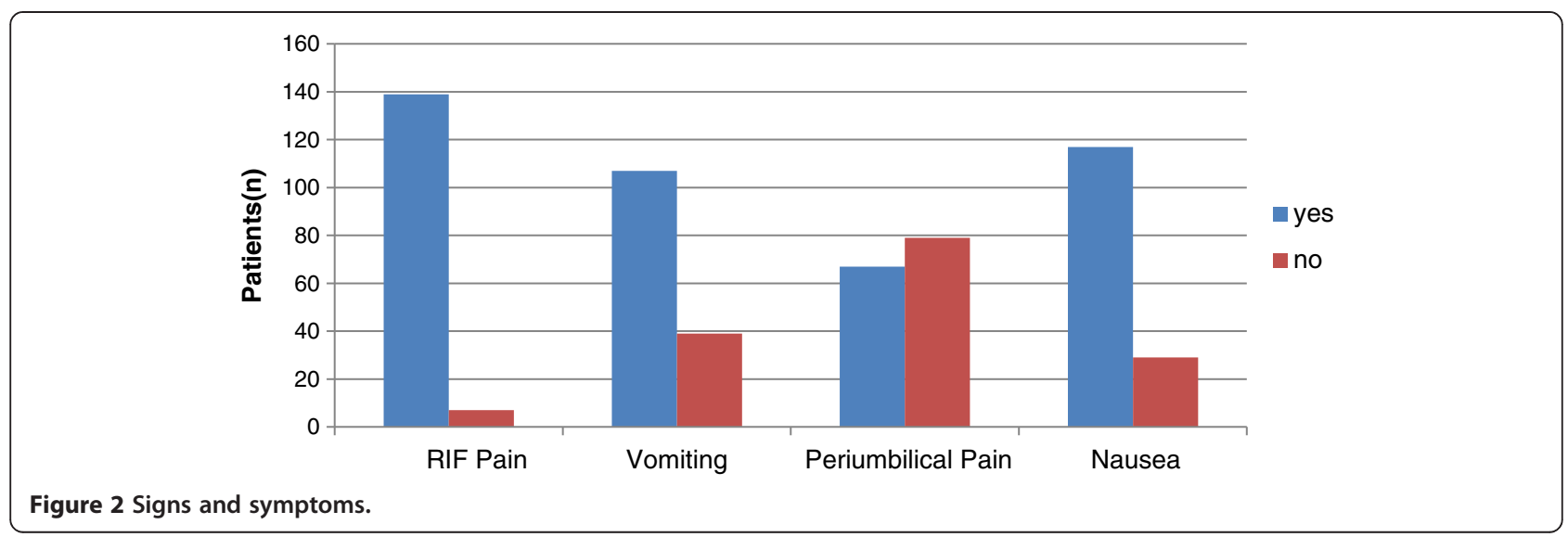

felt in the RIF in $95 \%$ of patients, vomiting in $73 \%$, and nausea in $80 \%$, while the typical clinical presentation as described in the standard textbooks was found in 31\% of the 146 studied patients. The overall complicated appendicitis rate was $31 \%$. Walker and Segal found that 210 patients out of a total of 24,000 surgical admissions presented with acute appendicitis at $\mathrm{CHBAH}$, while Murchison Hospital, in Southern Kwazulu Natal, reported only seven cases of acute appendicitis out of 8,000 admissions, with a potential population draining of 200,000 people to this particular hospital [9]. At Frere Hospital, Rogers et al. estimated acute appendicitis at 17 admissions per month in 2006 [10]. We estimate the current average in our hospital (CHBAH) at 25 cases per month. In the literature, the peak incidence of acute appendicitis worldwide is between 10 and 30 years of age [1]. In agreement with this, our study shows that acute appendicitis is common in young adults with an average age of 26 years ( $\mathrm{SD}=12$ years); $62 \%(91 / 146)$ of patients included in our study were male, which confirms previous findings that $67 \%(143 / 212)$ and 33\% (69/212) of patients presented with acute appendicitis to CHBAH were male and female, respectively [11]. Indeed, our study shows a statistically significant difference in the occurrence of complicated appendicitis regarding gender (Table 4). Most importantly, this finding

Table 1 Results of clinical findings and diagnostic investigations in all patients

\begin{tabular}{lllll}
\hline Investigation & Sensitivity (\%) & Specificity (\%) & PPV (\%) & NPV (\%) \\
\hline Fever $(n=146)$ & 18 & 83 & 95 & 5 \\
WCC $(n=139)$ & 48 & 75 & 84 & 28 \\
CRP $(n=135)$ & 92.5 & 24 & 80 & 50 \\
$\begin{array}{l}\text { Ultrasound } \\
(n=60)\end{array}$ & 60 & 66 & 89 & 31 \\
CT Scan $(n=6)$ & 100 & 100 & 100 & 100 \\
\hline
\end{tabular}

PPV: Positive predictive value in percentage. NPV: Negative predictive value in percentage. further confirms the predominance of acute appendicitis in young males.

The average duration of symptoms in our study was $4.5 \pm 4$ days. Compared to other studies, the average duration of symptoms before seeking medical attention was high, which might explain the heightened rate of complicated appendicitis found in our study. Victor et al. found that the mean duration of illness prior to seeking medical attention was 3.7 days, while Chamisa, at Prince Mshiyeni Memorial Hospital, found delays of $4 \pm 3.5$ days in presentation $[12,13]$. Importantly, our study confirms a statistically significant difference in patients with uncomplicated and complicated appendicitis after two days of symptoms $(P<0.001)$. Indeed, our finding is in agreement with various studies showing that the rate of complicated appendicitis increased two days after onset of symptoms $[2,8,14]$. Hayden et al. reported the risk of perforation at $70 \%$ after 48 hours of symptom onset [14]. Eldar et al. showed that the risk of perforation is minimal before 36 hours after onset of symptoms, but increases thereafter [15].

The present study included all the standard different investigations required in the diagnosis of acute appendicitis cases. We found the inflammatory marker, CRP, sensitive in up to $92 \%$ of cases and WCC in $48 \%$, with NPVs of CRP and WCC being 50\% and 28\%, respectively. Ahmad et al. found the CRP sensitivity to be $93 \%$ and the specificity $86 \%$, while the total leukocyte count had a NPV of $50 \%$ and CRP had a NPV of $50 \%$ [16]. Bearing in mind that ultrasound is operator-dependent, we found sensitivity to be $60 \%$, specificity $66 \%$, PPV $86.9 \%$, and NPV 31\%. In contrast, Al-Ajerami found an ultrasound sensitivity of $84.8 \%$ and a specificity of $83.3 \%$, with a PPV and a NPV of $93.3 \%$ and $66.7 \%$, respectively [6]. In general, ultrasound seems to have better PPV than NVP. Our study shows, as many previous studies have shown, that CT scanning is the best method of investigation to confirm or to invalidate the diagnosis of appendicitis $[17,18]$. 


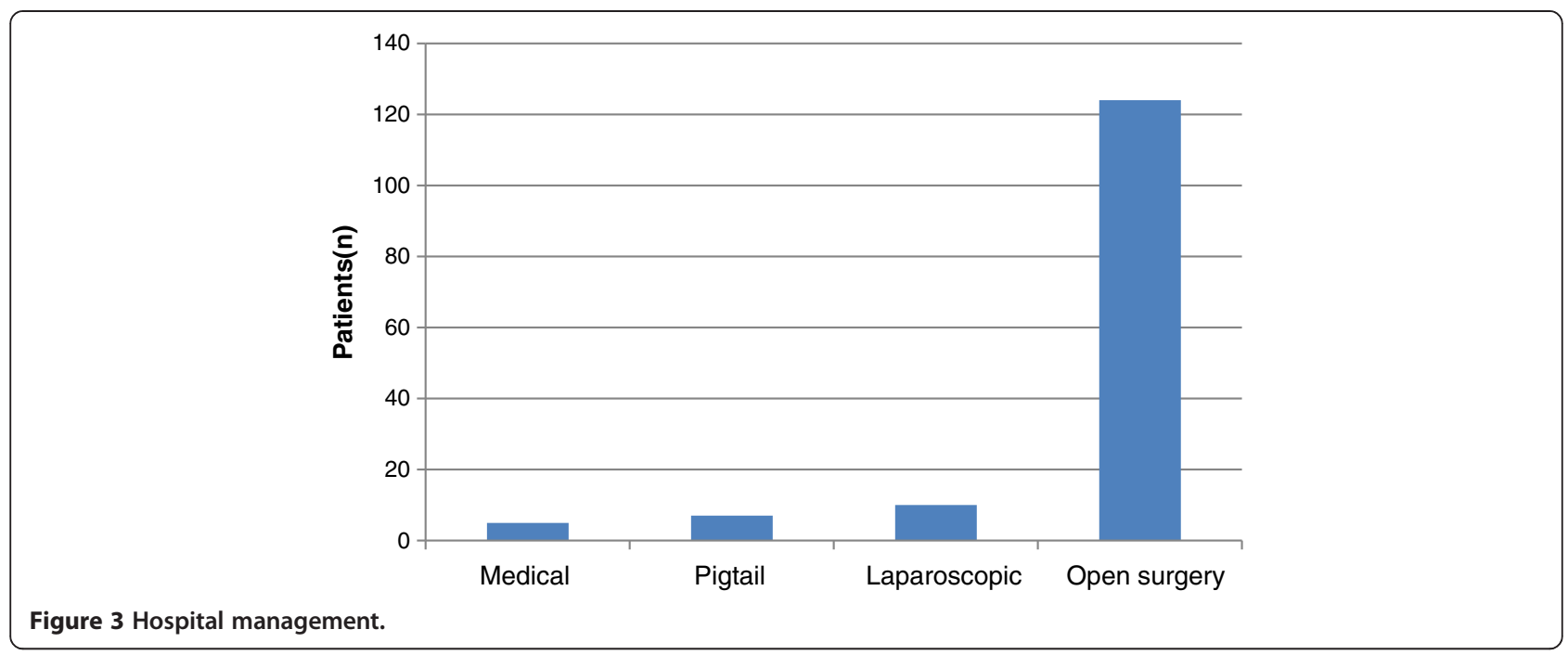

Our study shows that $63 \%$ of patients presented with delays, with the major reason for delay being lack of disease awareness and health facilities. Of those who presented late, $30 \%$ had self-medicated; $19 \%$ of the delayed presentations had been treated previously by general practitioners and most of these patients had been put on antibiotics. Thirty percent of acute appendicitis cases in our study were complicated appendicitis. Levy et al., in their audit of 1997, found the rate of perforation at CHBAH to be $22 \%$. Madiba et al., at King Edward VIII Hospital in Durban, showed a perforated appendicitis rate of $34 \%$ and has associated this with delayed presentation [19]. Victor et al., at Edendale Hospital, found perforation of appendix cases to be 57\% (114/200), of which $19 \%(38 / 200)$ were referred from the surrounding primary healthcare clinics and 2.5\% (5/200) were referred from local general practitioners [13]; referrals from the four rural referral hospitals constituted 35\% (70/200) of admissions. In our study we found a lower rate of perforation compared to that of other hospitals in South Africa, such as Edendale Hospital and Frere Hospital [10,12,13]. Our study shows that $83 \%$ of all admissions underwent surgery. In their trial of treating acute appendicitis with antibiotics, Vons et al. found that $12 \%$ of patients on antibiotherapy underwent appendicectomy during the first 30 days, while $30 \%$ underwent appendicectomy between 1 month and 1 year later [20]. Hanson et al. found that

Table 2 Histological findings

\begin{tabular}{ll}
\hline Histology findings & Number (\%) \\
\hline Perforated appendix/generalized peritonitis & $41(28.7)$ \\
Gangrenous appendicitis & $9(6.6)$ \\
Inflamed appendix & $38(26)$ \\
Normal appendix & $16(10.9)$ \\
Missing & $42(28.7)$ \\
\hline
\end{tabular}

Table 3 Comparison of complicated and uncomplicated appendicitis

\begin{tabular}{|c|c|c|c|}
\hline Parameter & $\begin{array}{l}\text { Uncomplicated } \\
\text { number (\%) }\end{array}$ & $\begin{array}{l}\text { Complicated } \\
\text { number (\%) }\end{array}$ & $P$ value \\
\hline Male & $56(55.45)$ & $35(77.78)$ & \multirow{2}{*}{0.01} \\
\hline Female & $45(44.55)$ & $10(22.22)$ & \\
\hline Average age $\pm S D$ & $26 \pm 12$ & $25 \pm 13$ & 0.791 \\
\hline \multicolumn{4}{|l|}{ Duration of symptoms } \\
\hline$<2$ days & $39(38.61)$ & $2(4.44)$ & \multirow[t]{2}{*}{$<0.001$} \\
\hline$>2$ days & $62(61.39)$ & $43(95.56)$ & \\
\hline Previous GP treatment & $12(42.86)$ & $16(57.14)$ & $<0.001$ \\
\hline \multicolumn{4}{|l|}{ Temperature } \\
\hline$<37.5^{\circ} \mathrm{C}$ & 87 (70.16) & $8(36.36)$ & \multirow[t]{2}{*}{0.514} \\
\hline$>37.5^{\circ} \mathrm{C}$ & $14(63.64)$ & $8(36.36)$ & \\
\hline \multicolumn{4}{|l|}{ WCC } \\
\hline$<12 \times 10^{9} / \mathrm{L}$ & $49(35)$ & $25(18)$ & \multirow[t]{2}{*}{0.102} \\
\hline$>12 \times 10^{9} / \mathrm{L}$ & $39(28)$ & $25(18)$ & \\
\hline \multicolumn{4}{|l|}{ CRP } \\
\hline$<10 \mathrm{mg} / \mathrm{L}$ & $13(14)$ & $1(3)$ & \multirow[t]{2}{*}{0.06} \\
\hline$>10 \mathrm{mg} / \mathrm{L}$ & $79(86)$ & $36(97)$ & \\
\hline \multicolumn{4}{|l|}{ ICU admission } \\
\hline$<2$ days & $5(4.95)$ & $9(20)$ & \multirow[t]{2}{*}{$<0.001$} \\
\hline$>2$ days & $1(0.99)$ & $11(24.44)$ & \\
\hline \multicolumn{4}{|l|}{ Hospital stay } \\
\hline$<2$ days & $39(38.61)$ & $2(4.44)$ & \multirow[t]{2}{*}{$<0.001$} \\
\hline$>2$ days & $62(61.39)$ & $43(95.56)$ & \\
\hline Mortality & $0(0.00)$ & $2(1.37)$ & $<0.001$ \\
\hline
\end{tabular}

The $P$ values for categorical variables were derived from two-tailed $x^{2}$ test or Fisher's exact test; $P$ values for continuous variable were derived from Student's $t$-test. 
Table 4 Comparison of findings in complicated appendicitis

\begin{tabular}{|c|c|c|c|c|}
\hline Parameter & $\begin{array}{l}\text { Inflammatory } \\
\text { mass } \\
\text { number (\%) }\end{array}$ & $\begin{array}{l}\text { Appendix } \\
\text { abscess } \\
\text { number (\%) }\end{array}$ & $\begin{array}{l}\text { Generalized } \\
\text { peritonitis } \\
\text { number (\%) }\end{array}$ & $P$ value \\
\hline Male & $2(50)$ & $7(87.5)$ & $26(78.78)$ & \multirow{2}{*}{0.004} \\
\hline Female & $2(50)$ & $1(12.5)$ & 7 (21.22) & \\
\hline Average age $\pm S D$ & $27 \pm 16$ & $20 \pm 10$ & $25.8 \pm 13$ & 0.777 \\
\hline \multicolumn{5}{|l|}{$\begin{array}{l}\text { Duration of } \\
\text { symptoms }\end{array}$} \\
\hline$<2$ days & $1(1.33)$ & $3(4)$ & $14(18.67)$ & \multirow[t]{2}{*}{0.049} \\
\hline$>2$ days & $3(4.73)$ & $5(7.04)$ & $25(33.80)$ & \\
\hline $\begin{array}{l}\text { Previous GP } \\
\text { treatment }\end{array}$ & $1(3.75)$ & $3(10.71)$ & $13(46.43)$ & 0.008 \\
\hline \multicolumn{5}{|l|}{ Temperature } \\
\hline$<37.5^{\circ} \mathrm{C}$ & $4(100)$ & $7(87.5)$ & $31(81.58)$ & \multirow[t]{2}{*}{0.92} \\
\hline$>37.5^{\circ} \mathrm{C}$ & $0(0)$ & $1(12.5)$ & $7(18.42)$ & \\
\hline WCC & & & & \multirow[t]{3}{*}{0.160} \\
\hline$<12 \times 10^{9} / \mathrm{L}$ & $3(4)$ & $3(4)$ & $15(20)$ & \\
\hline$>12 \times 10^{9} / \mathrm{L}$ & $0(0)$ & $4(6.35)$ & $20(31.75)$ & \\
\hline \multicolumn{5}{|l|}{ CRP } \\
\hline$<10 \mathrm{mg} / \mathrm{L}$ & $1(7.14)$ & $0(0.00)$ & $0(0.00)$ & \multirow[t]{2}{*}{0.003} \\
\hline$>10$ mg/L & $2(1.74)$ & $7(6.09)$ & 31 (26.96) & \\
\hline \multicolumn{5}{|l|}{ ICU admission } \\
\hline$<2$ days & $1(2.44)$ & $0(0.00)$ & $1(2.44)$ & \multirow[t]{2}{*}{$<0.001$} \\
\hline$>2$ days & $3(2.74)$ & $8(7.63)$ & $37(35.5)$ & \\
\hline \multicolumn{5}{|l|}{ Hospital stay } \\
\hline$<2$ days & $0(0.00)$ & $3(21.43)$ & $8(57.14)$ & \multirow[t]{2}{*}{$<0.001$} \\
\hline$>2$ days & $0(0.00)$ & $2(16.69)$ & $9(75)$ & \\
\hline Mortality & $0(0.00)$ & $0(0.00)$ & $2(1.37)$ & $<0.001$ \\
\hline
\end{tabular}

The $P$ values for categorical variables were derived from two-tailed $x^{2}$ test or Fisher's exact test; $P$ values for continuous variables were derived from Student's $t$-test.

$23 \%$ of appendicectomies take place after a failure to initial anti-biotherapy [21]. The treatment of acute appendicitis with antibiotics requires specific protocols and thorough follow-up of the patients.

Our study shows that outcome strongly depends on the presentation of acute appendicitis (uncomplicated or complicated), the age at presentation, the duration of symptoms, re-operations, and ICU stays of more than two days, and that hospital stays of longer than two days in complicated appendicitis were significant compared to cases of uncomplicated appendicitis. This was also found in other studies which assessed the outcome in cases of acute appendicitis $[12,13]$. In our study, the overall mortality rate is $2 / 146(1.37 \%)$; patients who died were above 45 years of age. Our mortality rate was acceptable compared to acceptable mortality rate of $<1 \%$. Similarly, Chamisa, at Prince Mshiyeni Memorial Hospital, reported a mortality of $1.2 \%$, with all cases from the perforated group [12] and Victor et al., at Edendale Hospital, reported an overall mortality rate of $2 \%$ [13]. All of the patients who died in the study by Victor et al. had intraabdominal contamination in all four quadrants and all patients required initial ICU admission [13].

Furthermore, our study shows that elderly patients who contract acute appendicitis have an atypical clinical presentation, most often with associated co-morbidities such as diabetes and hypertension. For this reason, the elderly patient requires particular attention: the correct diagnosis to be made as soon as possible and accurate investigations being essential if there is any doubt in the diagnosis of possible appendicitis.

\section{Conclusions}

Patients with acute appendicitis rarely present with a typical history of vague peri-umbilical pain. Leukocyte count is not reliable in the diagnosis of acute appendicitis. Most of our patients present late, with complicated diseases, and the most common reason for delay in presentation being a lack of disease awareness and/or health facilities and prior treatment by general practitioners. Complications were higher in males and the elderly.

\section{Abbreviations}

CHBAH: Chris Hani Baragwanath Academic Hospital; CRP: C-reactive protein; ICU: Intensive care unit; NPV: Negative predictive value; PPV: Positive predictive value; RIF: Right iliac fossa; WCC: White cell count.

Competing interests

The authors declare that they have no competing interests.

\section{Authors' contributions}

RN designed the study, participated in data collection, analysis of the data, has written the first manuscript. TE L and D K participated in Data collection and revised the manuscript. All authors contributed to the manuscript and approved the final version.

Received: 1 May 2013 Accepted: 3 February 2014

Published: 17 February 2014

\section{References}

1. John M, Kirkwood KS: Appendix. In Sabiston Textbook of Surgery. Biological Basis of Modern Surgical Practice. Edited by. Philadelphia: Saunders Elsevier; 2008:1333-1347.

2. Chaitan K, Eden J, Daniel S, Angela S, Francois I: Effect of delay in presentation on rate of perforation in children with appendicitis. Am J Emerg Med 2011, 29(8):890-893.

3. Doherty GM: Appendix. In Current Diagnosis and Treatment. Edited by Doherty GM. New York: McGraw Hill; 2010:615-620.

4. De Castro MM, Unlu C, Steller EP, Van Wangersveld BA, Vrouenraets BC: Evaluation of the appendicitis inflammatory response scores for patients with acute appendicitis. World J Surg 2012, 36(7):1521-1524.

5. Sengupta A, Bax G, Peterson-Brown S: White cell count and C-reactive protein measurement in patients with possible appendicitis. Ann $R$ Coll Surg Engl 2009, 91:113-115.

6. Al-Ajalemi Y: Sensitivity and specificity of ultrasound in the diagnosis of acute appendicitis. East Mediterr Health J 2012, 18:66-69.

7. Wilms IMHA, De Hoog D, De Visser DC, Janzing HJM: Appendectomy vs antibiotic treatment for acute appendicitis. Cochrane Database System Rev 2011, 11, CD008359

8. Ditillo MF, Dziura JD, Rabinovici R: Is it safe to delay appendectomy in adults with acute appendicitis? Ann Surg 2006, 244:656-660. 
9. Walker AR, Segal I: Effect of transition on bowel diseases in sub-Saharan Africans. Eur J Gasto Enterol Hepatol 1997, 9:207-210.

10. Rogers D, Hampton MI, Bunting M, Atherstone AK: Audit of appendicectomies at Frere hospital, Eastern Cape. S Afr J Surg 2008, 46(3):74-77.

11. Levy RD, Degiannis E, Kantarovsky A: Audit of acute appendicitis in a black South African population. S Afr J Surg 1997, 35(4):198-202.

12. Chamisa I: Clinicopathological review of 324 appendices removed for acute appendicitis in Durban. South Africa: a retrospective analysis. Ann R Coll Surg Engl 2009, 91:688-669.

13. Victor YK, Bojana B, Nikki LA, Jonathan H, Damian LC: Acute appendicitis in a developing country. World J Surg 2012, 36:2068-2073.

14. Hayden CK Jr, Kushelmeister J, Lipscomb TS: Sonography of acute appendicitis in childhood: perforation versus non perforation. J Ultrasound Med 1992, 11:209-216.

15. Eldar S, Nash E, Sabo E, Matter I, Kunin J, Mogilner GJ, Abrahamson J: Delay of surgery in acute appendicitis. Am J Surg 1997, 173:194-198.

16. Ahmad QA, Muneera MJ, Rasool MI: Predictive value of TLC and CRP in the diagnosis of acute appendicitis. Ann 2010, 16:116-119.

17. Terasawa T, Blackmore CC, Bent S, Kohlwes RJ: Systematic review: computed tomography and ultrasonography to detect acute appendicitis in adults and adolescents. Ann Intern Med 2004 141(7):537-546.

18. Doria AS, Moineddin R, Kellenburger CJ, Epelmen M, Beyene J, Schuh S, Babyn PS, Dick PT: US or CT for diagnosis of appendicitis in children and adults. Radiology 2006, 241:84-94.

19. Madiba TE, Haffejee AA, Mbete DL, Chaithram H, John J: Appendicitis among African patients at King Edward VIII Hospital, Durban, South Africa. East Afr Med J 1998, 75:81-84.

20. Vons C, Barry C, Maitre S, Pautrat K, Leconte M, Costaglioli B, Karoui M, Alves A, Dousset B, Valleur P, Falissard B, Franco D: Amoxicillin plus clavulanic acid versus appendicectomy for treatment of acute uncomplicated appendicitis: an open-label, non-inferiority, randomised controlled trial. Lancet 2011, 377:1573-1579.

21. Hanson J, Körner Ü, Ludwigs K, Johnsson E, Jönsson C, Lundholm K: Antibiotics as first line therapy for acute appendicitis: evidence for a change in clinical practice. World J Surg 2012, 36:2028-2036.

doi:10.1186/1865-1380-7-12

Cite this article as: Nshuti et al: Clinical presentation of acute appendicitis in adults at the Chris Hani Baragwanath academic hospital. International Journal of Emergency Medicine 2014 7:12.

\section{Submit your manuscript to a SpringerOpen ${ }^{\circ}$ journal and benefit from:}

- Convenient online submission

- Rigorous peer review

- Immediate publication on acceptance

- Open access: articles freely available online

- High visibility within the field

- Retaining the copyright to your article 